\title{
PENERAPAN MANAJEMEN ASET DENGAN MAPYOURTAG PADA PERGURUAN TINGGI
}

\author{
Khanna Tiara, S.Kom ${ }^{1}$ \\ Hendra Kusumah, S.Kom² \\ Dian Mustika Putri ${ }^{3}$ \\ Dosen STMIK Raharja Tangerang ${ }^{1,2}$, Mahasiswa STMIK Raharja Tangerang ${ }^{3}$ \\ J1 Jenderal Sudirman no.40, Modern, Cikokol Tangerang ${ }^{1,2,3}$ \\ Email : khanna.tiara@ raharja.info ${ }^{1}$, hendra.kusumah@ raharja.info $^{2}$, mustika@raharja.info ${ }^{3}$
}

\begin{abstract}
ABSTRAK
Di dalam suatu perusahaan, sistem manajemen aset yang baik sangat berperan penting dalam terciptanya manajemen perusahaan yang memiliki kinerja yang tinggi dalam hal pelayanan. Metode manajemen aset yang diterapkan, harus efektif dan efisien dalam pengimplementasiannya. Untuk saat ini metode manajemen aset yang diterapkan masih sangat konvensional yaitu dengan cara menulis laporan secara manual, kemudian laporan tersebut diinput kedalam aplikasi pengolah data, hal ini membuat sistem manajemen aset berjalan tidak efektif karena berjalan melalui proses yang sangat panjang. Untuk meningkatkan proses manajemen aset, maka diimplementasikan sebuah sistem barcode, dimana setiap barcode yang mewakili setiap aset menampilkan identitas dari setiap aset berupa tanggal dimulai pengoperasian, tipe dari setiap aset, beserta lokasi tempat setiap aset dioperasikan. Dengan barcode, proses manajemen aset yang ada di Perguruan Tinggi Raharja berjalan dengan efektif tanpa harus mencetak form ceklis dan data langsung ter-update dalam sebuah sistem database agar pengambilan keputusan terhadap aset yang dikelola berfungsi secara efektif yaitu dengan menggunakan aplikasi MapYourTag. Pada penelitian menggunakan metode mind-mapping dan metode analisa SWOT. Hasil dari penelitian ini berupa sebuah sistem aplikasi manajemen aset dengan melakukan scanning terhadap barcode yang telah dibuat untuk masing-masing aset yang terkoneksi langsung ke database yang memiliki dashboard yang menunjukkan statistika perlakuan kontrol pada setiap aset, sehingga pengawasan menjadi lebih efektif, optimal serta memudahkan dalam pembuatan laporan manajemen aset. Dan dengan adanya sistem ini, diharapkan manajemen aset yang diterapkan di Perguruan Tinggi Raharja dapat meningkatkan pengembangan berkelanjutan dalam daur hidup aset.
\end{abstract}

Kata Kunci: Barcode, MapYourTag, Manajemen Aset

\begin{abstract}
In an enterprise, good asset management system is very important role to creat an enterprise management that has a high performance in terms of service. Asset management methods which applied, must be effective and efficient in its implementation. Now, asset management methods which applied still very conventional that is with manually writing the report, then the report is inputted into a data processing application, this make an asset management system running ineffective because it through a very long process. To improve the asset management process, then implemented a barcode system, where each barcode representing each asset to show the identity of each asset in the form of the date of beginning the operation, the type of each asset,
\end{abstract}


along with the location of each asset operated. With the barcode, the asset management process at Perguruan Tinggi Raharja run effectively without having to print the form checklists and updated the data directly into a database system, so that decision-making on assets managed to effectively by using MapYourTag application. On this research, using mind-mapping and swot analysis methods. Results from this research in the form of asset management application system by scanning the barcode that has been created for each asset that are connected directly to a database that has a dashboard that shows statistics on each asset control treatment, so that monitoring become more effective, optimal and facilitate in making asset management reports. With this system, it is expected the asset management system that applied at Perguruan Tinggi Raharja can improve sustainable development in the the life cycle of an asset.

Keywords :Barcode, MapYourTag, Asset Management.

\section{PENDAHULUAN}

Semakin majunya perkembangan Teknologi Informasi di Indonesia menuntut seluruh masyarakat Indonesia beralih dari metode manual menjadi sistem yang berjalan dengan bantuan Teknologi dan Informasi. Begitupun dengan Perguruan Tinggi Raharja yang merupakan Perguruan Tinggi yang bergerak di bidang IT yang mempersiapkan SDM yang dapat bersaing di dunia perindustrian IT di Dunia.

Perguruan Tinggi Raharja merupakan Perguruan Tinggi yang memiliki sertifikasi ISO 9001:2008, yaitu sistem manajemen mutu ISO 9001 hasil revisi tahun 2008 yang menetapkan persyaratan-persyaratan dan rekomendasi untuk desain dan penilaian dari suatu sistem manajemen kualitas yang bertujuan untuk menjamin bahwa organisasi akan memberikan produk (barang/jasa) yang memenuhi persyaratan yang ditetapkan ${ }^{\text {(Gaspersz, 2002) }}$. Suatu lembaga/organisasi yang telah mendapatkan akreditasi (pengakuan dari pihak lain yang independen) ISO tersebut, dapat dikatakan telah memenuhi persyaratan internasional dalam hal manajemen penjaminan mutu produk atau jasa yang dihasilkannya.

Dan demi kelancaran dalam pengembangan Teknologi Informasi di Perguruan Tinggi Raharja, maka selain memerlukan sistem yang terus berkembang dalam bidang pendidikan, Perguruan Tinggi Raharja juga memerlukan sistem manajemen aset yang berkualitas. Sehingga, hal ini menuntut adanya perubahan dalam sistem yang digunakan demi terciptanya pendidikan dan manajemen kampus yang baik. 


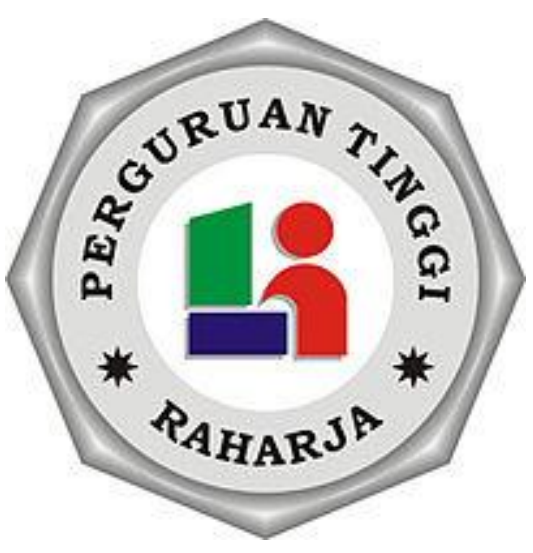

Perguruan Tinggi Raharja, memerlukan sebuah sistem dalam hal manajemen aset yang ada di kampus, agar manajemen aset di Perguruan Tinggi Raharja dapat berjalan optimal. Namun permasalahannya adalah manajemen aset yang diterapkan di Perguruan Tinggi Raharja masih sangat manual. Dimana, staff Divisi Operasi secara rutin seminggu sekali melakukan kontrol terhadap fasilitas kampus, dan kemudian setelah enam bulan, bagian Divisi Operasi menyerahkan form ceklis kepada Kabiro umum untuk dilihat data perlakukan kontrol pada setiap aset operasional tanpa ada data yang terekam secara sistematis. Sehingga, hal ini dibutuhkan sebuah sistem monitoring yang lebih sistematis, dimana seluruh laporan terhadap kerusakankerusakan ataupun perlakuan kontrol dapat dilihat secara menyeluruh dalam sebuah tampilan dashboard.

Dan dengan adanya sistem manajemen aset yang dimiliki kampus ini, Asisten Direktur Operasional dapat dengan mudah melakukan monitoring terhadap baik buruknya keseluruhan manajemen aset yang dilakukan oleh staff operasional Perguruan Tinggi Raharja. Serta, data yang telah diinput atau terekam dapat dilihat atau diperiksa hanya dengan melakukan scan barcode pada setiap barcode yang telah dibuatkan khusus untuk masing-masing aset yang dimiliki.

\section{PERMASALAHAN}

Prosedur sistem dalam monitoring aset yang ada pada Perguruan Tinggi Raharja pada saat ini masih sangat semi komputer, dimana pengecekan terhadap kondisi aset-aset yang ada pada saat ini masih berupa form ceklis biasa, yang setiap enam bulan sekali diganti dan kemudian diperbaharui kembali dengan form ceklis yang baru.

Namun perlu diketahui, bahwa monitoring yang dilakukan pada saat ini masih sangat tidak efektif. Selain adanya pemborosan dalam penggunaan kertas baru, pendataan atau pengecekan terhadap semua aset yang ada dikampus pun tidak terdata dengan baik atau tidak terekam dengan baik. Sehingga, apabila sewaktu-sewaktu data realnya dibutuhkan dalam penilaian kualitas manajemen kampus, bagian divisi operasi akan kebingungan dalam mencari data monitoring pada tanggal yang diinginkan. Karena terlalu banyak tumpukan-tumpukan kertas yang mesti dicari, dan hal ini menyebabkan kampus penuh dengan data-data sampah yang tidak terpakai. 


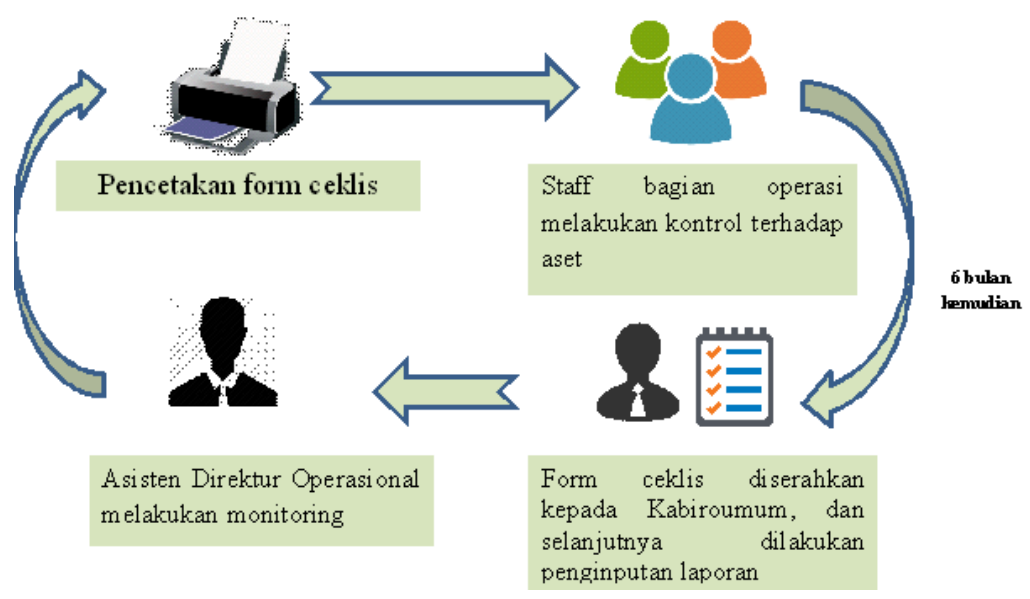

\section{Gambar 1. Alur Sistem Manajemen Aset pada Perguruan Tinggi Raharja}

Tidak efisiennya penerapan manajemen aset tersebut akan membuat tindakan terhadap perlakuan kontrol terhadap aset yang ada berjalan lamban dan sangat tidak efektif. Karena form ceklis yang dibagikan ke setiap staff bagian operasi memaksimalkan penggunaan kertas dan tinta untuk mencetaknya, tidak efektifnya pengawasan yang dilakukan oleh Asisten Direktur Operasional.

Maka, untuk mengatasi berbagai masalah tersebut, diperlukan sebuah sistem yang efektif dan efisien dalam melakukan monitoring terhadap manajemen aset kampus Raharja. Dari rumusan masalah tersebut menghasilkan beberapa pemecahan masalah, sistem yang berjalan dengan menggunakan barcode dapat termonitori dengan efektif karena tidak membutuhkan banyak kertas dalam pencetakan form ceklis, data dapat terkumpul secara sistematis hanya dengan membuatkan sebuah barcode untuk setiap aset yang ada di Perguruan Tinggi Raharja, keseluruhan laporan terhadap perlakukan kontrol yang dilakukan pada setiap aset di Perguruan Tinggi Raharja dapat terlihat pada sebuah dashboard.

Berdasarkan rumusan masalah yang telah teridentifikasi maka tujuan yang ingin dihasilkan adalah menciptakan sistem yang memberikan kemudahan dalam perlakukan kontrol terhadap aset, menciptakan sebuah sistem yang dapat menunjukkan laporan manajemen aset secara keseluruhan sehingga nantinya dapat digunakan untuk evaluasi dan kontrol semua aset yang ada. Sehingga dengan adanya sistem ini, laporan manajemen dapat dilakukan dengan cepat dan lebih baik untuk menentukan keputusan di periode yang akan datang.

\section{LITERATURE REVIEW}

Literature review merupakan tujuan, ringkasan menyeluruh dan analisis kritis terhadap penelitian yang tersedia yang relevan dan sastra non-penelitian tentang topik yang dipelajari ${ }^{\text {(Hart, }}{ }^{1998)}$. Banyak penelitian yang sebelumnya dilakukan mengenai pengembangan sistem berbasis barcode dalam berbagai ruang lingkup. Dalam pembuatan sistem berbasis barcode ini perlu dilakukan studi pustaka sebagai salah satu dari penerapan metode penelitian yang akan dilakukan. Berikut ini adalah 10 penelitian yang telah dilakukan dan memiliki kolerasi yang searah dengan penelitian yang akan dibahas dalam Jurnal ini diantaranya : 
1. Penelitian yang dilakukan oleh Ahmad Jamal dan Lies Yulianto pada tahun 2013, penelitian ini berjudul "Rancang Bangun Sistem Informasi Aplikasi Kasir Menggunakan Barcode Reader Pada Toko Dan Jasa Widodo Komputer Ngadirojo Kabupaten Pacitan". Penelitian ini dimulai dari proses observasi dan wawancara, adanya sistem informasi mempengaruhi berbagai aspek termasuk aspek penjualan, yang biasanya sistem penjualannya masih konvensional dan berpeluang terjadi kesalahan. Maka dari suatu permasalahan tersebut dibuatkan sistem informasi penjualan secara komputerisasi yang akan membuat lebih efisien dan keakuratan data penjualan. Oleh karena itu, akan dirancang Bangun Sistem Informasi Aplikasi Kasir Menggunakan Barcode Reader sebagai obyek kerja praktik. Dengan adanya sistem informasi penjualan tersebut dapat membantu petugas kasir dalam proses pengelolaan data penjualan yang lebih efisien dan akurat.

2. Penelitian yang dilakukan oleh I Dewa Made Widia pada tahun 2015, penelitian ini berjudul "Pengembangan Sistem Informasi Parkir Menggunakan Barcode". Penelitian ini memaparkan bahwa perkembangan kendaraan roda dua dan roda empat yang semakin pesat, tidak diimbangi dengan sistem pengaturan parkir yang memadai pada suatu tempat akan berdampak pada pengaturan parkir yang tidak teratur dan mengakibatkan waktu terbuang percuma dengan mencari kendaraan yang kita parkir. Untuk mengatasi permasalahan tersebut maka diciptakan suatu prototype sistem pengaturan parkir menggunakan barcode berbasis atmega 8535 agar sistem parkir lebih rapih dan teratur, alat ini memanfaatkan Barcode Scanner untuk mengidentifikasi kode barcode sebagai input software pada komputer kemudian output dari komputer akan mengerjakan speaker serta mengerjakan mikrokontrol Atmega 8535, kemudian dari Atmega 8535 ini akan mengolah input dari komputer untuk mengerjakan Motor DC membuka dan menutup serta LED yang berfungsi sebagai indikasi tempat parkir.

3. Penelitian ini dilakukan oleh Bambang Tri Atmojo, Sri Ratna Sulistyanti, dan Emir Nasrullah pada tahun 2013, penelitian ini berjudul "Model Sistem Kendali Pintu Otomatis Menggunakan Barcode Berbasis PC (Personal Computer) Pada Gerbang Laboratorium Teknik Elektro Unila". Penelitian ini menjelaskan bahwa Laboratorium adalah salah satu sarana yang sangat penting untuk menunjang belajar dan penelitian di Jurusan Teknik Elektro Unila. Terkadang pekerjaan atau penelitian tidak terselesaikan dijam kerja dilanjutkan diluar jam kerja. Saat ini jurusan hanya mengandalkan surat izin agar mahasiswa dapat melakukan kegiatan diluar jam kerja, namun solusi ini kurang efektif untuk menciptakan keamanan dan kondusif di laboratorium Teknik Elektro. Untuk itu perlu dibuatkan sebuah model pintu otomatis agar tidak semua mahasiswa dapat masuk ke laboratorium diluar jam kerja. Model pintu otomatis ini menggunakan barcode yang terdapat pada kartu ID sebagai sandi untuk membuka pintu. Dengan menggunakan scanner barcode sebagai sensor untuk membaca barcode dan ditambah mikrokontroler ATMEGA 8535 sebagai pengendali motor servo.

4. Penelitian ini dilakukan oleh Mita Pramihapsari dan Messa Prima Kaldera pada tahun 2012, penelitian ini berjudul "Perancangan Labelling Pada Dokumen Menggunakan QR 
Code". Penelitian ini menjelaskan bahwa penggunaan QR Code sebagai label dari suatu dokumen merupakam alternatif baru dalam pengamanan dokumen. Sistem pelabelan ini dapat menunjang pengadministrasian dokumen karena data informasi diolah secara terkomputerisasi. Penerapan public key infrastructure dapat menunjang pengamanan pada dokumen karena data/informasi mengenai dokumen tersebut telah dienkripsi terlebih dahulu dan diberi digital signature sebelum dienkripsi dengan QR Code.

5. Penelitan ini dilakukan oleh Apriana dan Hernowo Danusaputro yang berjudul "Pembuatan Software Pencatat Pengunjung Perpustakaan Menggunakan Barcode dan MySQL berbasis Borland Delphi 7.0". Sistem dengan barcode dan MySQL berbasis Borland Delphi 7.0 ini memudahkan dalam mencatat pengunjung pada sebuah perpustakaan dan data yang ditampilkan lebih akurat dan menyeluruh. Dari penelitian yang dilakukan didapatkan bahwa software Borland Delphi 7.0 dapat membaca record pada database MySQL dengan baik dan tampilan pada monitor sesuai dengan data pengunjung yang tersimpan pada database.

6. Penelitian yang dilakukan oleh Aswin Chandrasekharan, Nikhail Venkat, Aniruddha P.B, dan Siva Rama Krishnan Somayaji pada tahun 2013 yang berjudul "Barcode Enabled Event Management System for Logistics and Consumables Management”. Event management has a complex set of processes which involve registration, secured venue access, real time stock taking of consumables and crowd-management. A system that integrates all these requirements is scarce. Hence, there is a dire need to build an automated system which can cater to the needs of any event management. This paper discusses the importance of using barcode based authentication mechanism for event management. This was beneficial in two folds - One, it helped in retaining delegate enthusiasm due to smaller waiting queues and second, it meant that a smaller area needed to be assigned to the venue-access personel.

7. Penelitian ini dilakukan oleh Baysari MT, Lehnbom EC, dan Westbrook JI pada tahun 2013, penelitian ini berjudul "Bar code medication administration system". Bar code medication administration (BCMA) systems are now adopted by the majority (65.5\%) of American hospitals to allow patient identity verification and electronic checking of orders 1 . The nurse scans a bar code on their identification tag, the patient's wrist-band, and the medication to be admin-istered. This information is compared with details in the electronic medication administration record (eMAR) and if a mismatch is detected, the nurse is alerted, typically via a visual or auditory warning on the computer screen. BCMA systems are potentially effective in reducing administration errors when designed well and used correctly, but the evidence for improved patient out-comes with these systems is less clear.

8. Penelitian ini dilakukan oleh K. Varsha, Jyoti Choudhary, Madhuri Kodgi, dan M. S Indira pada tahun 2015, penelitian ini berjudul "Barcode and RFID Based Security System". Often in colleges, students run a risk of misplacement or theft of their valuables. A security system was designed and developed for safety of the belongings of the students in the 
college. It includes the basic information, schematic, circuit diagram, technical details of the systems used like RFID (Radio Frequency Identification) and Barcode system and design/test data of the developed security system. The RFID and Barcode based cost effective Security System is designed and developed using commercially graded components suiting the basic requirements of the system. The integration of both RFID and Barcodes generates a project with wider boundaries and effective solutions.

9. Penelitian yang dilakukan oleh Winston Rey S. Aguirre, Jayson P. Bartolome, John Erik T. De Torres, Mark Joseph P. Fajilan, Erwin Z. Mendoza, dan Jake M. Laguador pada tahun 2013, penelitian ini berjudul "Automated Laboratory Item-Inventory System with Barcode". The Barcode reader, which is the hardware of the system, is very easy to handle, for it automatically gives details for the scanned device or unit. Automated Laboratory ItemInventory System $w /$ Barcode retrieves and stores data of the user and the item being borrowed. After the successful process of entering the username and password, and getting confirmation from the user, the software will then send data to the data storage so that it will show history, for it to checks a device or unit being borrowed.

10. Penelitian yang dilakukan oleh K.Lakshmi Sudha, Shirish Shinde, dan Titus Thomas pada tahun 2015, penelitian ini berjudul "Barcode based Student Attendance System". This project uses a barcode scanner. B.B.S.A.S uses Barcode scanner to take the attendance of students entering the lab. Each student's ID card will have a barcode at the back side of it. This barcode contains unique data of the student such as roll number, branch and year. Etc. Student will scan their barcode at the end so that the student can't cheat. The display screen will show the attendance of the particular student after scanning his/her barcode. Teachers and administrator will only have access to the system with their respective login ID's and passwords.

Setelah dilakukannya peninjauan terhadap sepuluh literature review yang ada, telah banyak research yang dilakukan terhadap implementasi sistem barcode dalam berbagai bidang serta berbagai dukungan aplikasi atau software yang digunakan. Karena proses monitoring terhadap aset operasional yang tersedia di Perguruan Tinggi Raharja masih dilakukan dengan cara manual dan belum terdata secara rapi dan sistematis. Maka dari itu, penulis membahas mengenai hal "Penerapan Manajemen Aset Dengan MapYourTag Pada Perguruan Tinggi" agar dapat lebih mempermudah Asisten Direktur Operasional dalam melakukan pengawasan terhadap aset-aset operasional yang ada di Perguruan Tinggi Raharja.

\section{PEMECAHAN MASALAH}

Untuk mengatasi berbagai masalah tersebut, maka diperlukan sebuah sistem yang efektif dan efisien dalam melakukan monitoring terhadap manajemen aset pada Perguruan Tinggi Raharja yang dimulai dari penerimaan aset, perpindahan aset, peminjaman aset, perbaikan aset, stock opname, sampai dengan proses reporting/pelaporan data. Dengan pengaplikasian sistem barcode pada setiap aset yang terdapat pada Perguruan Tinggi Raharja, maka kondisi semua aset yang 
berada di kampus dapat selalu terupdate kelayakannya. Karena dengan adanya barcode yang ditempelkan disetiap aset, bagian divisi operasi dapat langsung melakukan scan terhadap barcode tersebut, dan aplikasi MapYourTag akan langsung memproses barcode yang telah teridentifikasi dan memunculkan identitas barcode tersebut. Setelah itu, bagian divisi operasi dapat langsung memberikan laporan pengecekan aset tersebut. Serta laporan akan dikirim, dan langsung masuk ke dalam sebuah database sesuai dengan hari, tanggal, bulan dan waktu pengecekan.

Sehingga dengan adanya sistem aplikasi ini, Asisten Direktur Operasional dapat melakukan monitoring terhadap manajemenan aset yang ada di Perguruan Tinggi Raharja. Dan dengan cara ini, dapat dengan mudah melihat hasil dari pengecekan rutin seminggu sekali atau bahkan setiap hari, serta dapat meminimalisir penggunaan kertas.

\section{Mind Mapping}

Mind mapping merupakan salah satu solusi untuk meningkatkan kemampuan berfikir kreatif, karena dengan membuat mind mapping atau peta konsep dalam pembelajaran sama halnya dengan memberikan kesempatan kepada siswa untuk berkreasi, membuat catatan ringkas sesuai dengan kebutuhan siswa itu. Mind mapping mengarahkan pikiran siswa untuk bekerja dengan baik karena adanya desain visual, sehingga hal ini memungkinkan siswa dengan mudah melihat hubungan antara ide-ide, dan mendorong mereka untuk mengelompokkan ide-ide tersebut (Alamsyah: 2009)

Ditinjau dari segi waktu mind mapping juga dapat mengefisienkan penggunaan waktu dalam mempelajari suatu informasi. Hal ini utamanya disebabkan karena metode ini dapat menyajikan gambaran menyeluruh atas suatu hal, dalam waktu yang lebih singkat. Dengan kata lain, Mind mapping mampu memangkas waktu belajar dengan mengubah pola pencatatan linear yang memakan waktu menjadi pencatatan yang efektif yang sekaligus langsung dapat dipahami oleh individu.

Pada metode Mind Mapping ini menghasilkan sebagai berikut yaitu penjelasan tentang aplikasi MapYourTag yang merupakan MapYourTag is an easy to use cloud-based asset management system that enables you to track all your assets at a fraction of the cost. As an an easy-to-use cloud-based system MapYourTag gives you all the benefits of an asset management from your desktop web browser as well as your mobile app that you can download. Tujuan MapYourTag. Kekurangan MapYourTag yaitu sistem ini tidak bersifat open source. Kelebihan MapYourTag yaitu memiliki aplikasi berbasis barcode yang terkoneksi pada database sehingga memberi kemudahan dalam manajemen aset. User pada MapYourTag yaitu ADO, Kabiroumum, dan Staff Operasi . Lima point mind mapping tersebut diambil berdasarkan fakta yang sesungguhnya yang terjadi pada Perguruan Tinggi Raharja hasil dari penelitian yang dilakukan oleh peneliti. 


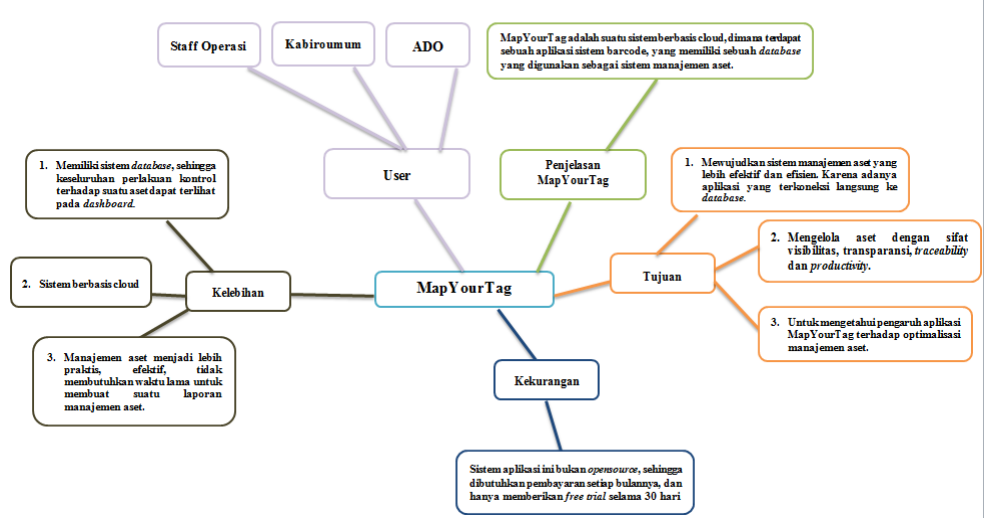

Gambar 2. Mindmap Aplikasi MapYourTag

\section{SWOT}

SWOT digunakan untuk menilai kekuatan-kekuatan dan kelemahan-kelemahan dari sumbersumber daya yang dimiliki perusahaan dan kesempatan-kesempatan eksternal dan tantangantantangan yang dihadapi ([Jogiyanto 2005]).

Pada pemecahan masalah menggunakan metode SWOT yang kemudian akan diaplikasikan untuk menemukan pembayaran online pada Perguruan Tinggi Raharja. Langkah - langkah tersebut dapat dijelaskan pada sebagai berikut :

\section{Tabel 1. Analisa SWOT}

\begin{tabular}{|c|c|c|}
\hline & STRENGTH (KEKUATAN) & WEAKNESS (KELEMAHAN) \\
\hline Faltor Eksternal & 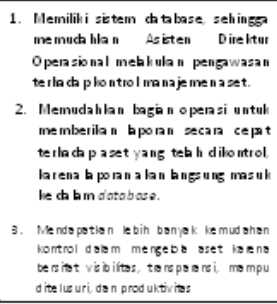 & 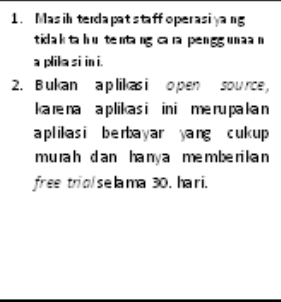 \\
\hline OPPORTUNTY (PELUANG) & STRATEGY SO & STRATEGY WO \\
\hline $\begin{array}{l}\text { 1. Manajemen aset menjadi lebih } \\
\text { efeltif dan efisien. } \\
\text { 2. Dibutuhkannya akses kontrol } \\
\text { bersif at onime dan reoitime. }\end{array}$ & 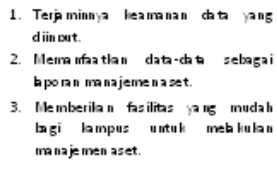 & $\begin{array}{l}\text { 1. Sosialisaci pengguraan aplilasi } \\
\text { manajemen aet lepada seluruh } \\
\text { staff operasi. } \\
\text { 2. Menyiaplan dana ang alan } \\
\text { dikeluarlan untuk pengguraan } \\
\text { aplikasi ini }\end{array}$ \\
\hline THREAT (ANCAM AN) & STRATEGY ST & STRATEGY WT \\
\hline 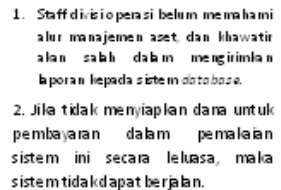 & $\begin{array}{l}\text { 1. Memberikan panduan kepada } \\
\text { staff operasi dalam } \\
\text { menggunakan aplikasi } \\
\text { MapYourTag. }\end{array}$ & $\begin{array}{l}\text { 1. Memberikan batasan } \\
\text { waktu kontrol aset. }\end{array}$ \\
\hline
\end{tabular}

Setelah membandingkan antara faktor eksternal peluang dan ancaman dengan faktor internal kekuatan dan kelemahan sehingga dari analisis tersebut dapat diambil suatu keputusan strategis suatu organisasi, yaitu sebagai berikut, Strategi SO yang didapatkan adalah terjaminnya 
keamanan data yang diinput, memanfaatkan data-data sebagai laporan manajemen aset, memberikan fasilitas yang mudah bagi kampus untuk melakukan manajemen aset. Strategi ST diterapkan berdasarkan perbandingan antara strength (kekuatan) dan thread (ancaman), yaitu dengan memanfaatkan strategi kekuatan yang dipunyai oleh perusahaan untuk dapat meminimalisir ancaman yang ada bagi perusahaan. Strategi yang didapatkan adalah memberikan panduan kepada staff operasi dalam menggunakan aplikasi MapYourTag. Strategi WO diterapkan berdasarkan perbandingan antara weakness (kelemahan) dan opportunity (peluang), yaitu dengan meminimalisirkan kelemahan yang dimiliki oleh perusahaan untuk dapat memaksimalkan banyak peluang yang bisa didapat oleh perusahaan. Strategi yang didapatkan adalah sosialisasi penggunaan aplikasi manajemen aset kepada seluruh staff operasi dan menyiapkan dana yang akan dikeluarkan untuk penggunaan aplikasi ini. Strategi WT diterapkan berdasarkan perbandingan antara weakness (kelemahan) dan thread (ancaman), yaitu dengan mengetahui kelemahan yang dipunyai oleh perusahaan untuk dapat segera meminimalisir ancaman yang akan mengancam perusahaan jika kelemahan tidak segera diatasi. Strategi yang didapatkan adalah memberikan batasan waktu kontrol aset.

\section{Flowchart Rancangan Aplikasi}

Flowchart adalah penggambaran secara grafik dari langkah-langkah dan urut-urutan prosedur dari suatu program ([Menurut Adelia 2011:116]). Flowchart program dalam pemecahan masalah merupakan keterangan yang lebih rinci tentang bagaimana setiap langkah program atau prosedur sesungguhnya akan dilaksakan. Flowchart ini menunjukan setiap langkah program atau prosedur dalam urutan yang tepat saat terjadi. Berikut flowchart manajemen aset dengan menggunakan MapYourTag pada Perguruan Tinggi Raharja:
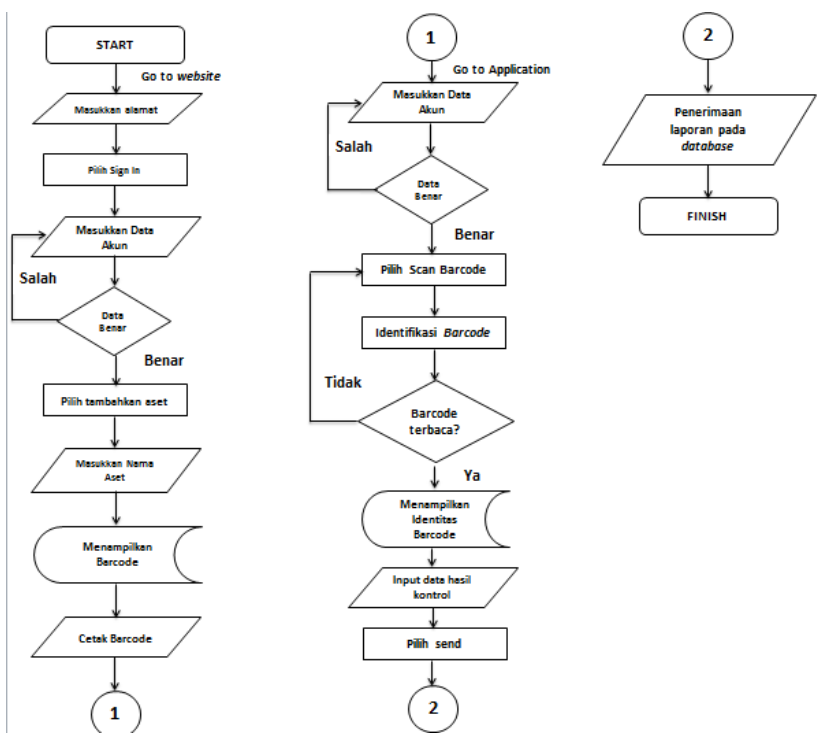

\section{Gambar 3. Flowchart Sistem Manajemen Aset dengan Menggunakan MapYourTag}

Dari gambar di atas dapat dijabarkan, bahwa hal pertama yang paling penting dilakukan oleh Asisten Direktur Operasional adalah memasukkan seluruh aset-aset yang ada di Perguruan 
Tinggi Raharja, dimana setiap asetnya memiliki sebuah barcode. Kemudian mengkonfigurasi user, dan selanjutnya user akan melakukan scanning barcode pada smartphone, dan smartphone akan menampilkan identifikasi dari setiap barcode. Dan kemudian tahap selanjutnya adalah dengan memasukkan laporan kontrol pada setiap aset dan mengirimnya secara langsung ke database agar Asisten Direktur Operasional dapat melihat keseluruhan laporan pada sebuah dashboard.

\section{PROTOTYPE}

Proses pengembangan sistem seringkali menggunakan pendekatan prototipe (prototyping). Metode ini sangat baik digunakan untuk menyelesesaikan masalah kesalahpahaman antara user dan analis yang timbul akibat user tidak mampu mendefinisikan secara jelas kebutuhannya ([Mulyanto 2009]). Prototype adalah proses pembuatan model sederhana software yang mengizinkan pengguna memiliki gambaran dasar tentang program serta melakukan pengujian awal. Prototype memberikan fasilitas bagi pengembang dan pemakai untuk saling berinteraksi selama proses pembuatan, sehingga pengembang dapat dengan mudah memodelkan perangkat lunak yang akan di buat. Pada prototype sistem manajemean aset ini merupakan gambaran saat menggunakan sistem MapYourTag:

\section{Konfigurasi Aset dengan Pilih Menu +Create Asset}

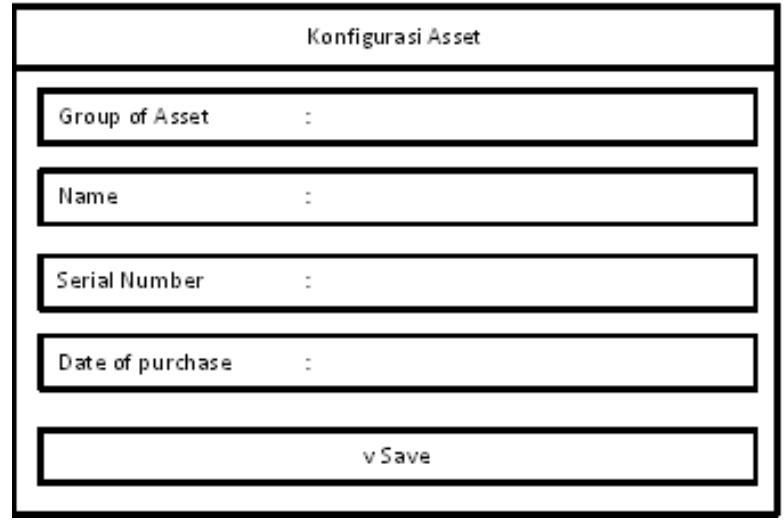

Prototype 1. Konfigurasi Aset

\section{Konfigurasi Users dengan pilih menu Manage Users}

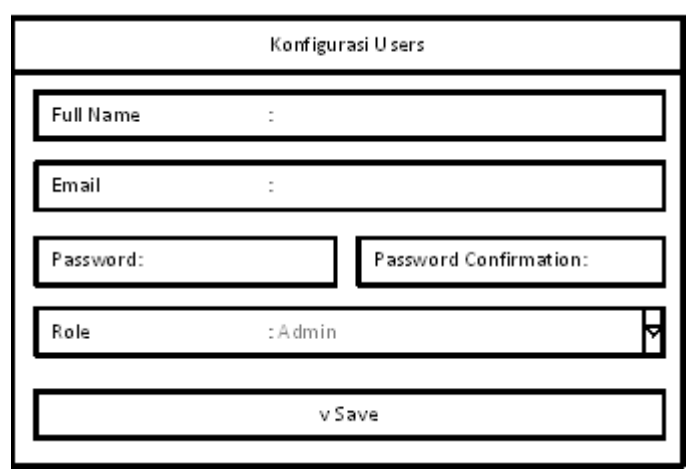

Prototype 2. Konfigurasi Users 


\section{Scanning Barcode pada smartphone}

Scan QR Code or Barcode

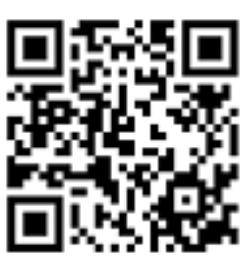

Dashboard

Sign Out

Prototype 3. Scanning Barcode

4. Barcode teridentifikasi, Pilih Save dan laporan akan terkirim ke database

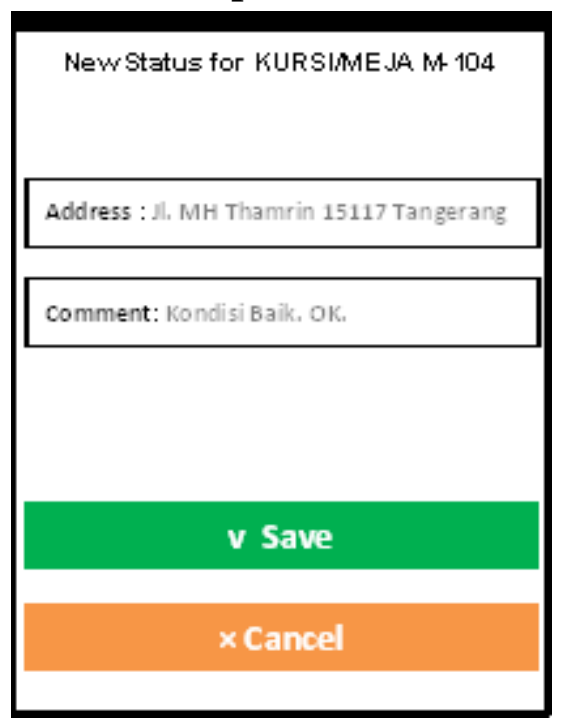

\section{IMPLEMENTASI}

Prototype 4. Identifikasi Barcode

Sistem manajemen aset dengan menggunakan aplikas MapYourTag ini diimplementasikan pada Perguruan Tinggi Raharja

1. Asisten Direktur Operasional Sign-up akun MapYourTag, kemudian melakukan Sign-In

ADO membuat akun MapyourTag, mengisi data secara lengkap, ADO kedudukannya sebagai Owner sistem. 


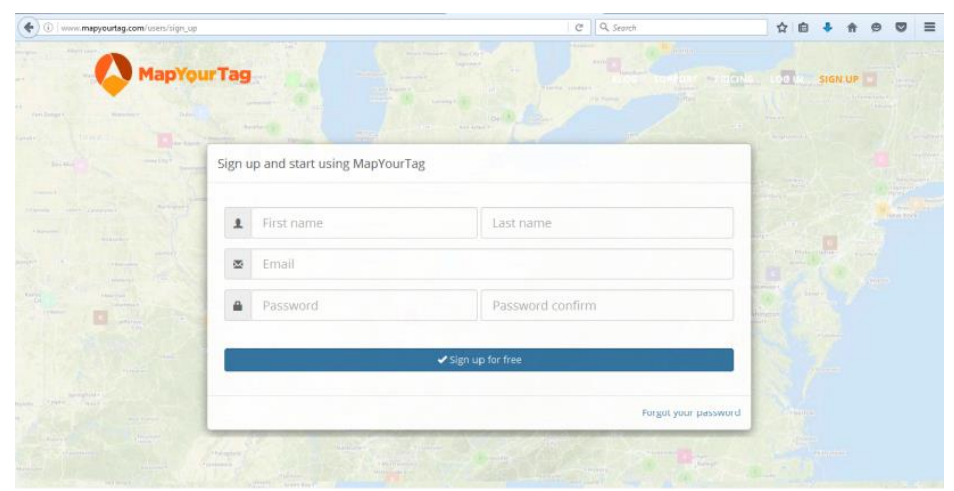

Gambar 4. Sign-up Akun

\section{Masuk ke dalam dashboard MapYourTag}

Berikut merupakan tampilan dashboard MapYourTag, dimana laporan yang telah masuk ke database akan terkumpul pada bagian ini.

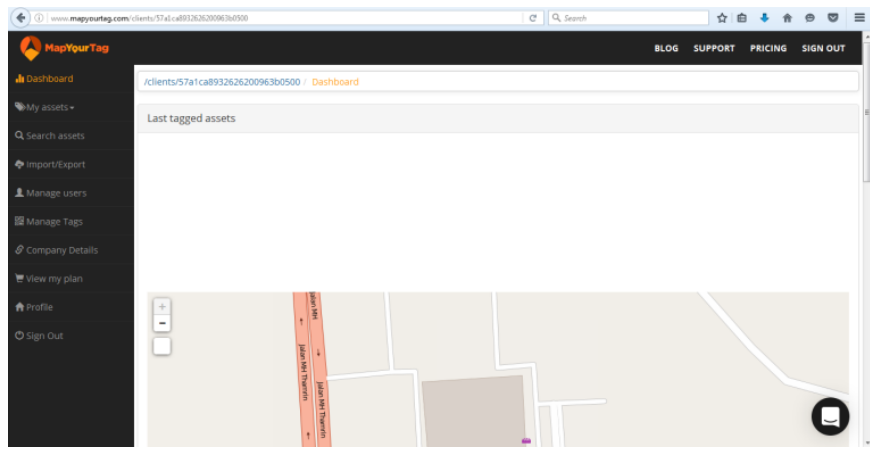

\section{Gambar 5. Tampilan dashboard database MapYourTag}

\section{Pilih My Assets, kemudian pilih +Create new assets}

Masukkan semua aset yang ada di Perguruan Tinggi Raharja, berdasarkan grup aset yang dibuat sebelumnya.

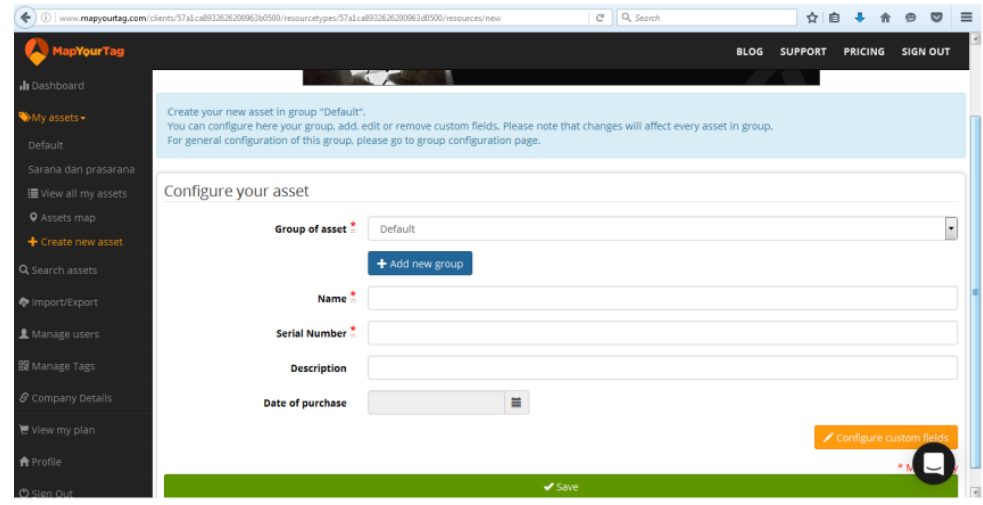

Gambar 6. Konfigurasi Aset

Setelah dibuat grup aset, maka langsung memasukkan nama-nama aset sesuai grupnya, sebagai contoh berikut, pada grup AC, dimasukkan nama aset AC Ruang LV-209. Maka, barcode akan terlihat, dan barcode inilah yang nantinya akan dicetak dan ditempel dimasing-masing aset. 


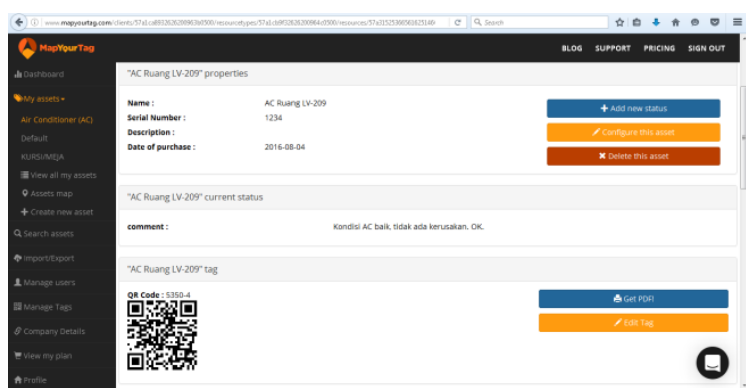

Gambar 7. Menampilkan data aset beserta barcode

\section{Input defined roles}

Memasukkan akun-akun yang akan berperan dalam pengembangan sistem ini, seperti operator yang akan dipegang oleh Kabiroumum, dan admin yang akan dipegang oleh seluruh staff operasional yang bertugas.

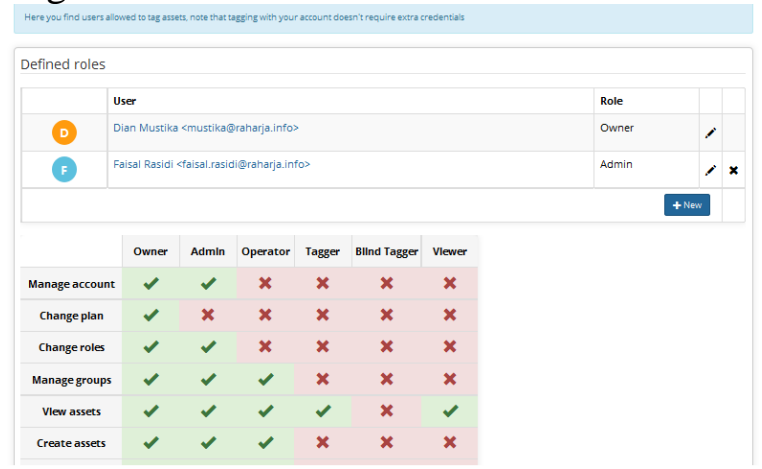

\section{Gambar 8. Konfigurasi user}

\section{Install aplikasi MapYourTag}

Setelah keseluruhan aset terdata pada database, maka seluruh staff operasional yang telah terdaftar akunnya pada database MapYourTag Perguruan Tinggi Raharja, melakukan installing aplikasi MapYourTag pada smartphone masing-masing.

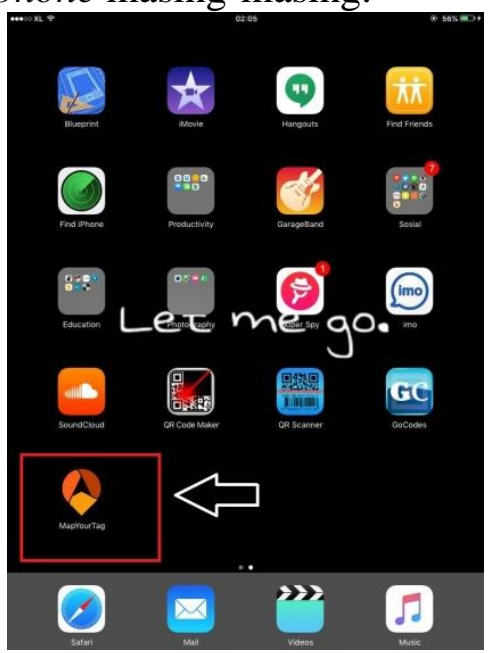

Gambar 9. Aplikasi MapYourTag yang telah terinstall 


\section{Scanning Barcode}

Setelah berhasil sing-in, maka akan muncul tampilan berikut ini. Pilih Scan QR Code or Barcode

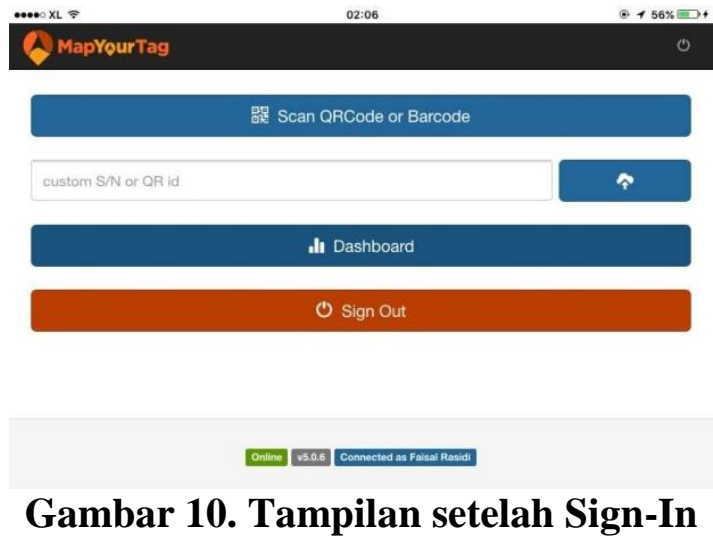

Maka akan mulai melakukan scanning barcode

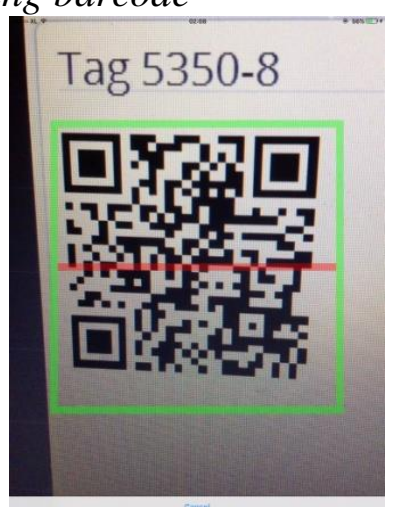

Gambar 11. Scanning Barcode

\section{Identifikasi barcode}

Setelah barcode berhasil teridentifikasi, maka akan muncul tampilan seperti ini

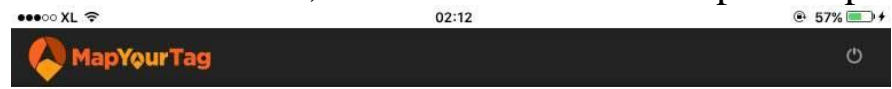

New Status for KURSI/MEJA RUANG M-104

Address Jalan MH Thamrin 15117 Tangerang

comment $^{*} \quad$ Kondisi baik. OK

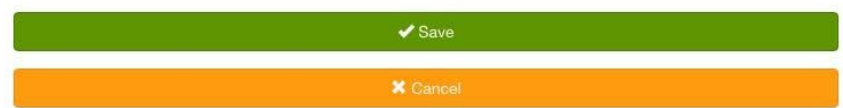

Gambar 15. Barcode yang telah teridentifikasi 
Setelah muncul tampilan seperti diatas, maka bagian staff yang melakukan kontrol, memasukkan laporan data kontrol pada kolom comment dan pilih Save.

\section{Penerimaan data pada database}

Setelah diinput kondisi aset yang telah dikontrol, maka tampilan dashboard nya seperti ini

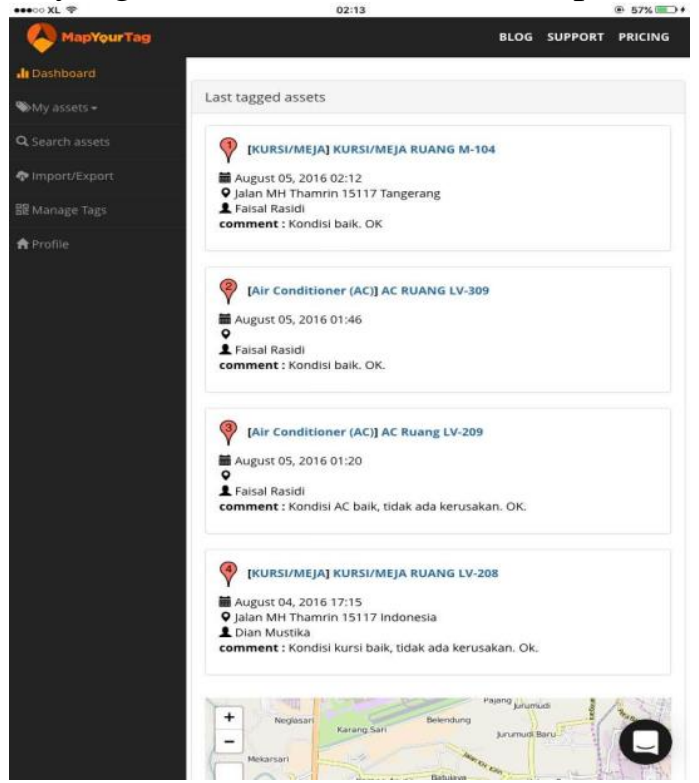

Gambar 16. Tampilan Dashboard pada aplikasi MapYourTag

\section{KELEBIHAN MapYourTag}

Mewujudkan sistem manajemen aset yang lebih efektif dan efisien. Karena dengan adanya aplikasi yang terkoneksi langsung ke database ini, dalam manajemen aset tidak harus melakukan cetak form ceklis dan menumpuk banyak kertas. Manajemen aset menjadi lebih praktis, efektif, tidak membutuhkan waktu lama untuk membuat suatu laporan manajemen aset. Dengan adanya dashboard yang menunjukkan statistika perlakuan kontrol pada setiap aset, pengawasan menjadi lebih efektif dan optimal. Jika sewaktu-waktu data diperlukan untuk melihat kualitas manajemen kampus, maka data manajemen aset dapat langsung terlihat secara sistematis berdasarkan grup aset yang telah dibuat, dan disertai juga dengan waktu perlakuan kontrol pada setiap aset.

\section{KELEMAHAN MapYourTag}

Sistem ini tidak bersifat open source, sehingga apabila Perguruan Tinggi Raharja ingin mengimplementasikan ini, harus menyiapkan biaya yang akan dikeluarkan setiap bulannya untuk sistem manajemen aset ini. Untuk menggunakan sistem ini juga diperlukan fasilitas pendukung, yaitu berupa smartphone yang dapat sinkron dengan sistem database. Sehingga identifikasi barcode tidak mengalami kendala. Dan smartphone yang terkoneksi internet tersebut, dapat langsung mengirim laporan ke database secara online. 


\section{KESIMPULAN}

Dengan demikian dapat disimpulkan, penelitian ini menggunakan metode mind-mapping dan analisa SWOT. Menggunakan sistem manajemen aset secara online dengan adanya sistem barcode yang langsung terkoneksi ke sistem database manajemen aset tersebut lebih efektif, efisien, aman, dan cepat dibandingkan dengan sistem manajemen aset secara manual yang diterapkan sebelumnya pada Perguruan Tinggi Raharja. Pengembangan sistem manajemen dengan menggunakan scan barcode memudahkan bagian operasi dalam melakukan kontrol pada setiap aset yang ada, karena tidak harus mencetak kertas dan menumpukkan banyak kertas dalam melakukan pengawasan, pengendalian dan pengambilan keputusan pada aset-aset yang ada di Perguruan Tinggi Raharja. Dengan adanya sistem manajemen aset online pada Perguruan Tinggi Raharja diharapkan dapat memberikan kemudahan kepada seluruh bagian staff operasi dalam melakukan kontrol terhadap semua aset yang secara cepat, akurat dan efisien sesuai kebutuhan yang telah dianalisa dengan menggunakan metode SWOT yang dapat meningkatkan mutu manajemen Perguruan Tinggi Raharja.

\section{DAFTAR PUSTAKA}

1. Aguirre, Winston Rey S., Jayson P. Bartolome, John Erik T. De Torres, Mark Joseph P. Fajilan, Erwin Z. Mendoza, and Jake M. Laguador. "Automated Laboratory ItemInventory System with Barcode". International Journal of Emerging Technology and Advanced Engineering, (ISSN 2250-2459, ISO 9001:2008 Certified Journal, Vol. 3, Issue 12, December 2013.

2. Apriana, dan Hernowo Danusaputro. "Pembuatan Software Pencatat Pengunjung Perpustakaan Menggunakan Barcode dan MySQL berbasis Borland Delphi 7.0”. Jurnal Berkala Fisika, Vol. 12, No. 4, Oktober 2009.

3. Artikel Tips Terbaru. 2014. Manajemen Aset: Pengertian dan Manfaat Bagi Perusahaan. $\begin{array}{lllll}\text { Diakses } & \text { pada } & 27 & \text { November } & 2014\end{array}$ https://tipscaradanlangkah.wordpress.com/tag/fungsi-manajemen-aset/.

4. Atmojo, Bambang, dkk. "Model Sistem Kendali Pintu Otomatis Menggunakan Barcode Berbasis PC (Personal Computer) Pada Gerbang Laboratorium Teknik Elektro Unila”. Jurnal Rekayasa dan Teknologi Elektro, Volume 7, No. 2, Mei 2013.

5. Baysari MT, Lehnbom EC and Westbrook JI. "Bar code medication administration system”. Vol. 1, Issue 1, June 2013.

6. Chandrasekharan, Aswin, Nikhail Venkat, Aniruddha P.B, and Siva Rama Krishnan Somayaji. "Barcode Enabled Event Management System for Logistics and Consumables Management". International Journal of Advanced Research in Computer and Communication Engineering ISSN 2278-1021, Vol. 2, Issue 11, November 2013. 
7. Choudhary, Jyoti, K. Varsha, Madhuri Kodgi and M.S Indira. "Barcode and RFID Based Security System”. International Journal of Engineering Innovation \& Research, ISSN: 2277 - 5668, Vol. 4, Issue 2, 2015.

8. Cronin, Patricia., Frances Ryan, Michael Coughlan. "Undertaking a literature review: a step-by-step approach”. British Journal of Nursing, Vol.17, No 1, 2008.

9. Ernawati, Fitri. 2013. JURNAL 3 : Analisa SWOT. Blog Pribadi. Diakses pada 6 Mei 2013 dari http://dunia-ritel.blogspot.co.id/2013/05/analisa-swot.html.

10. GetApp. 2016. MapYourTag Reviews. Diakses pada 1 Agustus 2016 dari https://www.getapp.com/operations-management-software/a/mapyourtag/reviews/.

11. Jamal, Ahmad dan Lies Yulianto. "Rancang Bangun Sistem Informasi Aplikasi Kasir Menggunakan Barcode Reader Pada Toko Dan Jasa Widodo Komputer Ngadirojo Kabupaten Pacitan". Journal Speed Sentra Penelitian Engineering dan Edukasi, Vol. 5, No 3, 2013.

12. Pekei, Beni., Djumilah Hadiwidjojo, Sumiati Djumahir. "The Effectiveness Of Local Asset Management (A Study On The Government Of Jayapura)". International Journal of Business and Management Invention, Volume 3, Issue 3, March 2014.

13. Pramihapsari, Mita dan Messa Prima Kaldera. "Perancangan Labelling Pada Dokumen Menggunakan QR Code”. Jurnal Teknik Komputer, Vol. 20, No.1, Februari 2012.

14. Riswanto, Pebri Prandika Putra. "The Use of Mind Mapping Strategy in the Teaching of Writing at SMAN 3 Bengkulu, Indonesia”. International Journal of Humanities and Social Science, Vol. 2, No. 21, November 2012.

15. Subrata, Karno. Analisis dan Perancangan Sistem. Diambil dari: "http://www.academia.edu/6228702/Flowchart_Jurnal".

16. Sudha, K. Lakshmi, Shirish Shinde, and Titus Thomas. "Barcode based Student Attendance System”. International Journal of Computer Application 0975 - 8887, Vol. 119, No.2, June 2015.

17. Suhartini. "Analisa SWOT Dalam Menentukan Strategi Pemasaran Pada Perusahaan”. Jurnal MATRIK Teknik Industri Universitas Muhammadiyah Gresik, Vol.12, No.2, Maret 2012.

18. Tiara, Khanna. 2016. Tahapan Pembuatan Jurnal. Diakses pada 26 Mei 2011 dari http://khanna.ilearning.me/tahapan-pembuatan-jurnal/

19. Widia, I Dewa Made. "Pengembangan Sistem Informasi Parkir Menggunakan Barcode". Jurnal Cendekia ISSN: 1693-6094, Vol 13, No.1, Januari 2015. 
20. Umiyati. Pengaruh Sistem Manajemen Mutu ISO 9001:2008 dan Partisipasi Penyusunan Anggaran Terhadap Kinerja Manajerial. Etikonomi, Vol. 14, ISSN 1412-8969, April 2015.

21. Zulfiandri, Dyah Citra Wardhani."Rancang Bangun Sistem Informasi Manajemen Aset Berbasis Private Cloud (Studi Kasus: TVRI Nasional)”. Jurnal SimanteC, Vol. 5, No.1, Desember 2015. 